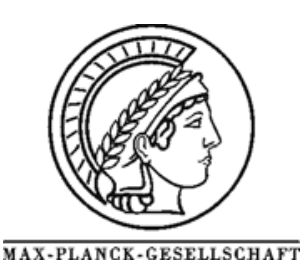

\title{
Analysis of Silica-Supported Vanadia by X-ray Absorption Spectroscopy: combined theoretical and experimental studies
}

\author{
M. Cavalleri ${ }^{1}$, K. Hermann ${ }^{1}$, A. Knop-Gericke ${ }^{2}$, M. Hävecker ${ }^{2}$, R. Herbert ${ }^{2}$, C. Hess ${ }^{2,3}$, \\ A. Oesterreich ${ }^{2}$, J. Döbler ${ }^{4}$, R. Schlögl ${ }^{2}$
}

\begin{abstract}
${ }^{1}$ Theory Dept., Fritz-Haber-Institut der Max-Planck-Gesellschaft, Faradayweg 4-6, 14195 Berlin, Germany; ${ }^{2}$ Inorg. Chem. Dept., Fritz-Haber-Institut der Max-Planck-Gesellschaft, Faradayweg 4-6, 14195 Berlin, Germany ${ }^{3}$ Eduard-Zintl-Institut für Anorganische und Physikalische Chemie, Technische Universität Darmstadt, Petersenstr. 20, 64287 Darmstadt, Germany

${ }^{4}$ Institut für Chemie, Humboldt-Universität zu Berlin, Unter den Linden 6, 10099 Berlin, Germany

*Corresponding author: e-mail cavall@fhi-berlin.mpg.de, hermann@fhi-berlin.mpg,de
\end{abstract}

Received 17 December 2008, Accepted 17 December 2008, Available online 22 January 2009.

\begin{abstract}
In this study we combine density-functional theory (DFT) calculations on oxygen core excitations in vanadia-silica model clusters with experimental in situ X-ray absorption fine structure (NEXAFS) near the oxygen K edge of vanadia model catalysts supported by SBA-15 silica in order to identify structural details of the vanadia species. The silica support is found to contribute to the NEXAFS spectrum in an energy range well above that of the vanadium oxide units allowing a clear separation between the corresponding contributions. Further, differently coordinated oxygen which is characteristic for particular vanadia species, monomeric or polymeric, can be clearly identified in the theoretical spectra in agreement with the oxygen K-edge NEXAFS measurements. The comparison of the theoretical and experimental NEXAFS spectra provides clear evidence that under in situ conditions different molecular vanadia species, in particular polymeric $\mathrm{VO}_{\mathrm{x}}$, exist at the catalyst surface and the exclusive presence of monomeric vanadia groups can be clearly ruled out. The present analysis goes beyond earlier work applying vibrational spectroscopy to the present systems where, as a result of extended vibrational coupling, a separation between vanadia, silica, and interface contributions is less successful.
\end{abstract}

Keywords: vanadium oxide on SBA-15; density-functional theory; X-ray absorption (NEXAFS)

\section{Introduction}

The importance of support material for the catalytic activity of oxide-based materials is widely acknowledged but not understood in great detail. It is well known that the choice of the support material can modify the activity of vanadia catalysts by several orders of magnitude [1-4]. Here the reducibility of the oxide support seems to have a large influence on the catalytic activity and it is often assumed that VO-support bonds, coupling the vanadia species with the support, rather than vanadyl $\mathrm{V}=\mathrm{O}$ or bridging $\mathrm{V}$ $\mathrm{O}-\mathrm{V}$ bonds of the vanadia species contribute to the site specific reactivity of supported vanadia [2-5]. Alterna- tively, the role of the support may be limited to providing specific binding sites for vanadia surface species such as monomeric or polymeric, and, thus, may be restricted to determining the relative amount of differently coordinated oxygen centers in the catalyst [6]. Despite major efforts to examine the importance of the oxide-support interface on an experimental basis, mainly using vibrational spectroscopy, no definitive picture has been obtained so far.

The initially accepted view [5] of monomeric $\mathrm{VO}_{\mathrm{x}}$ species dominating the catalytic activity was based on the interpretation of vibrational spectra of supported vanadia catalysts. It implies that the identification of differently coordinated oxygen centers and the differentiation between 
(a)

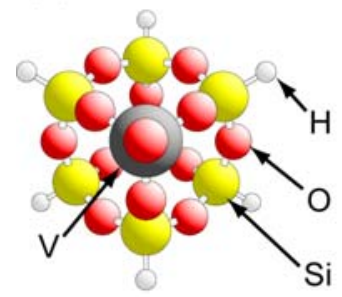

(e)
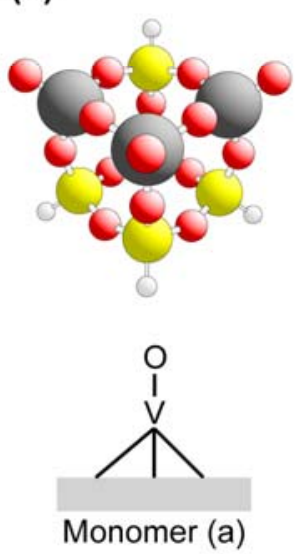

(b)

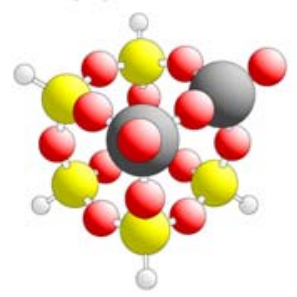

(f)
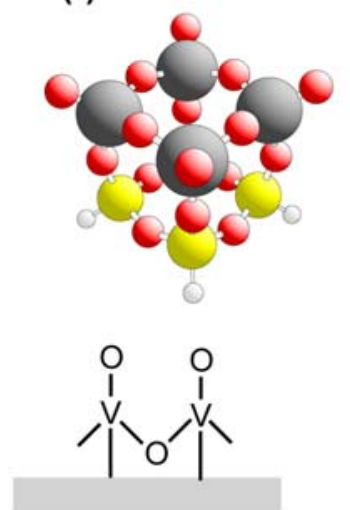

Polymer (b-f) (c)

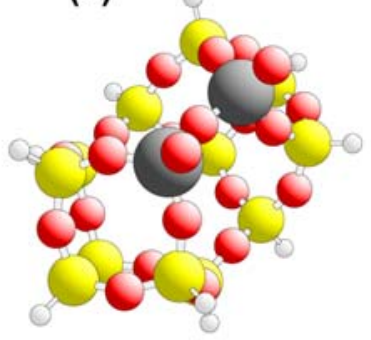

(g)
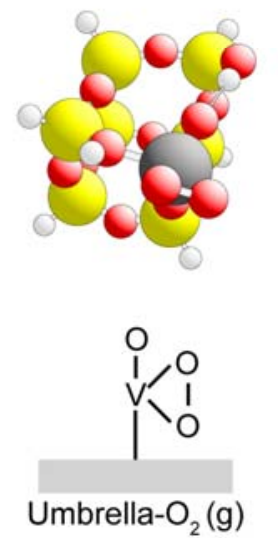

(d)

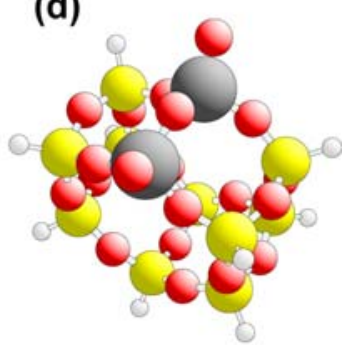

(h)
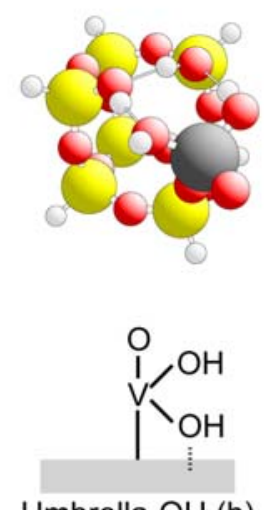

Fig. 1: Geometric structures of the clusters used to model silica-supported vanadia units in pyramidal conformation, (a) VSi $\mathrm{O}_{13} \mathrm{H}_{7}$, (b) $\mathrm{V}_{2} \mathrm{Si}_{6} \mathrm{O}_{14} \mathrm{H}_{6}$, (c) $\mathrm{V}_{2} \mathrm{Si}_{12} \mathrm{O}_{23} \mathrm{H}_{12}$, and (d) $\mathrm{V}_{2} \mathrm{Si}_{10} \mathrm{O}_{20} \mathrm{H}_{10}$, taken from ref. [7] and (e) $\mathrm{V}_{3} \mathrm{Si}_{5} \mathrm{O}_{15} \mathrm{H}_{5}$, (f) $\mathrm{V}_{4} \mathrm{Si}_{4} \mathrm{O}_{16} \mathrm{H}_{4}$, taken from ref. [15]. Clusters (g) $\mathrm{VSi}_{7} \mathrm{O}_{15} \mathrm{H}_{9}$ and $(\mathrm{h}) \mathrm{VSi}_{7} \mathrm{O}_{15} \mathrm{H}_{11}$ represent peroxo $(\mathrm{SiO})-\mathrm{V}=\mathrm{O}\left(\mathrm{O}_{2}\right)$ and hydroxylated $(\mathrm{SiO})-\mathrm{V}=\mathrm{O}(\mathrm{OH})_{2}$ umbrella geometries [15], see text. Large dark and light balls refer to vanadium and silicon, respectively, while smaller dark balls denote oxygen and small light gray balls visualize hydrogen. The binding schemes of the clusters are sketched at the bottom.

monomeric and polymeric $\mathrm{VO}_{\mathrm{x}}$ species can be achieved by evaluating the presence of a band in the $950 \mathrm{~cm}^{-1}$ range of the vibrational spectrum reflecting $\mathrm{V}-\mathrm{O}-\mathrm{V}$ bridging modes. As an additional indicator the shift of the $\mathrm{V}=\mathrm{O}$ vanadyl band near $1050 \mathrm{~cm}^{-1}$ was considered where the $\mathrm{V}=\mathrm{O}$ stretching vibration is assumed to be uncoupled from the other vibrations of the system. This view has been challenged recently by a systematic study [7] combining infrared absorption (IRAS) and Raman spectroscopy measurements with density-functional theory (DFT) calculations on model clusters. In a careful analysis the authors find that the vibrational $\mathrm{V}=\mathrm{O}$ and $\mathrm{Si}-\mathrm{O}$ bands are quite close in energy and corresponding vibrations may be coupled such that they cannot be used to indicate the presence of monomeric or polymeric $\mathrm{VO}_{\mathrm{x}}$ species. Further, vibrational bands referring to bridging $\mathrm{V}-\mathrm{O}-\mathrm{V}$ modes and characterizing polymeric vanadia species seem to overlap strongly with bands from the silica support. Finally, the vibrational band in the 950 $\mathrm{cm}^{-1}$ region is attributed to interface modes rather than to those of bridging $\mathrm{V}-\mathrm{O}-\mathrm{V}$ species observed in unsupported vanadia.

The discussion of possible uncertainties in the band assignments of the vibrational spectra of supported vanadia [7] has revived a debate in the literature concerning the structure of the monomeric vanadia species [8]. Here two different schemes of $\mathrm{VO}_{\mathrm{x}}$ binding with the support oxide have been suggested where the most common scheme assumes the $\mathrm{VO}_{\mathrm{x}}$ species to stabilize in a pyramidal structure with three VO-support bonds and one vanadyl $\mathrm{V}=\mathrm{O}$ bond, formally characterized as $(\mathrm{SiO})_{3}-\mathrm{V}=\mathrm{O}$. In the alternative "umbrella" model, the $\mathrm{VO}_{\mathrm{x}}$ unit, with one vanadyl $\mathrm{V}=\mathrm{O}$ bond and a peroxo group directly binding with $\mathrm{V}$, is anchored at the support oxide by only one interfacial $\mathrm{V}-\mathrm{O}-\mathrm{Si}$ bond $[9,10]$. A variation of the umbrella model is obtained when the perturbed $\mathrm{O}_{2}$ connected to the vanadium is replaced by two $\mathrm{OH}$ groups [11]. Both pyramidal $(\mathrm{SiO})_{3^{-}}$ $\mathrm{V}=\mathrm{O}$ and umbrella models are believed to coexist at the support surface with their relative weight depending on temperature, hydration degree, and synthetic conditions of the catalytic material [8]. In addition, recent FTIR studies on silica SBA-15 supported vanadia using NO as a probe molecule have evidenced bridging nitrates implying the presence of dimeric or polymeric species [12].

In this work we combine density-functional theory (DFT) calculations on oxygen core excitations in vanadiasilica model clusters with experimental in situ X-ray absorption fine structure (NEXAFS) near the oxygen $\mathrm{K}$ edge of vanadia model catalysts supported by SBA-15 silica in order to identify structural details of the vanadia species. NEXAFS spectroscopy [13], based on dipole excitation of highly localized core electrons by photons, has been proven to provide reliable atom specific information thus allowing to distinguish between atoms in different local environments. In the present study we use absorption due to oxygen $1 \mathrm{~s}$ core electron excitations to discriminate between different reactive oxygen sites (vanadyl $\mathrm{V}=\mathrm{O}$, bridging $\mathrm{V}$ - 
Table 1: Bond distances $d(\mathrm{~V}-\mathrm{O})$ and bond angles $\theta(\mathrm{V}-\mathrm{O}-\mathrm{V})$ for terminal vanadyl and bridging oxygen, $\mathrm{V}=\mathrm{O}(1)$ and $\mathrm{V}-\mathrm{O}(2)-\mathrm{V}$, in the model clusters shown in Fig. 1a-f. Distances are given in Ångstrom, angles in degrees.

\begin{tabular}{|l|c|c|c|}
\hline \multicolumn{1}{|c|}{ Cluster } & $\mathrm{d}(\mathrm{V}=\mathrm{O}(1))$ & $\mathrm{d}(\mathrm{V}-\mathrm{O}(2))$ & $\theta(\mathrm{V}-\mathrm{O}-\mathrm{V})$ \\
\hline (a) $\mathrm{VSi}_{7} \mathrm{O}_{13} \mathrm{H}_{11}$ & 1.58 & --- & 144.2 \\
\hline (b) $\mathrm{V}_{2} \mathrm{Si}_{6} \mathrm{O}_{14} \mathrm{H}_{6}$ & 1.57 & 1.78 & 163.6 \\
\hline (c) $\mathrm{V}_{2} \mathrm{Si}_{12} \mathrm{O}_{23} \mathrm{H}_{12}$ & 1.58 & 1.78 & 134.0 \\
\hline (d) $\mathrm{V}_{2} \mathrm{Si}_{10} \mathrm{O}_{20} \mathrm{H}_{10}$ & 1.58 & 1.79 & 144.4 \\
\hline (e) $\mathrm{V}_{3} \mathrm{Si}_{5} \mathrm{O}_{15} \mathrm{H}_{5}$ & 1.58 & 1.78 & 146.8 \\
\hline (f) $\mathrm{V}_{4} \mathrm{Si}_{4} \mathrm{O}_{16} \mathrm{H}_{4}$ & 1.58 & 1.78 & \multicolumn{2}{c|}{} \\
\hline
\end{tabular}

$\mathrm{O}-\mathrm{V}$, VO-support, $\mathrm{V}-\mathrm{O}_{2}$, and $\mathrm{V}-\mathrm{OH}$ ) in the silica-supported vanadia species discussed above. The results of the spectrum calculations can provide spectroscopic fingerprints for differently coordinated oxygen centers. This enables a detailed atom specific analysis of experimental data obtained for surface vanadia supported on the ordered mesoporous silicate, SBA-15 [14]. It allows, in particular, a discrimination of different vanadia species, monomeric or polymeric in different binding geometry, present at the support surface where the exclusive presence of monomeric vanadia groups can be clearly ruled out. Vanadium L edge NEXAFS spectra which are available in experiment with peak structures that lie energetically below but near those of the oxygen $\mathrm{K}$ edge have not been included in the present analysis due to missing spin-orbit coupling in the theoretical treatment.

In Section 2 we introduce the models and discuss details of the computational methods used in the spectrum calculations. Section 3 describes experimental details connected with sample preparation and NEXAFS measurements while Section 4 presents results and discussion. Finally, Section 5 summarizes our conclusions.

\section{Theoretical Details}

\subsection{Cluster models}

The present calculations are based on vanadia silica model clusters whose structures were obtained from geometry optimizations at the DFT level in studies on vibrational properties of silica-supported vanadia [7, 15], see Fig. 1. These clusters represent a wide variety of different arrangements of vanadia (monomeric and polymeric species) in a silica neighborhood of cubic ring and hexagonal prism structure. The simplest models with ring structure are derived from a polyhedral oligomeric silsequioxane (POSS) given by a $\mathrm{Si}_{8} \mathrm{O}_{12} \mathrm{H}_{8}$ cube with silicon occupying the corners and oxygen near the edge midpoints. Then the monomeric vanadia site in its pyramidal conformation which binds with three Si atoms of the support can be modeled by replacing one $\mathrm{SiH}$ moiety of the cube by a vandyl group $\mathrm{V}=\mathrm{O}$ which leads, after geometry optimization, to the
$\mathrm{VSi}_{7} \mathrm{O}_{13} \mathrm{H}_{7}$ cluster shown in Fig. 1a. Analogously, a dimeric VOV unit can be modeled by replacing a $\mathrm{Si}_{2} \mathrm{H}_{2} \mathrm{O}$ edge of the initial $\mathrm{Si}_{8} \mathrm{O}_{12} \mathrm{H}_{8}$ cube by a $\mathrm{V}_{2} \mathrm{O}_{3}$ group resulting in the $\mathrm{V}_{2} \mathrm{Si}_{6} \mathrm{O}_{14} \mathrm{H}_{6}$ cluster of Fig. 1b. As a larger model for the dimeric VOV species, designed to reduce possible strain effects due to the small size of the $\mathrm{V}_{2} \mathrm{Si}_{6} \mathrm{O}_{14} \mathrm{H}_{6}$ cluster, the $\mathrm{V}_{2} \mathrm{Si}_{12} \mathrm{O}_{23} \mathrm{H}_{12}$ cluster shown in Fig. 1c is considered. Another group of clusters has been derived [7] from sissesquioxane models with hexagonal prismatic structure characteristic of zeolites [16]. Of these we include the hexagonal prismatic $\mathrm{V}_{2} \mathrm{Si}_{10} \mathrm{O}_{20} \mathrm{H}_{10}$ model cluster, see Fig. $1 \mathrm{~d}$, which serves to study binding environments of the vanadia dimer differing from those of the clusters shown in Figs. 1b, c. Larger polymeric $\mathrm{VO}_{\mathrm{x}}$ species are modeled in the present study by a trimer cluster $\mathrm{V}_{3} \mathrm{Si}_{5} \mathrm{O}_{15} \mathrm{H}_{5}$ (replacing a $\mathrm{Si}_{3} \mathrm{H}_{3} \mathrm{O}_{2}$ edge of the $\mathrm{Si}_{8} \mathrm{O}_{12} \mathrm{H}_{8}$ by $\mathrm{V}_{3} \mathrm{O}_{5}$ ), see Fig. 1e, and a tetramer cluster $\mathrm{V}_{4} \mathrm{Si}_{4} \mathrm{O}_{16} \mathrm{H}_{4}$ (replacing a $\mathrm{Si}_{4} \mathrm{H}_{4} \mathrm{O}_{4}$ edge of the $\mathrm{Si}_{8} \mathrm{O}_{12} \mathrm{H}_{8}$ by $\mathrm{V}_{4} \mathrm{O}_{8}$ ), see Fig. 1f. Table 1 lists typical V$\mathrm{O}$ distances and $\mathrm{V}-\mathrm{O}-\mathrm{V}$ angles of the vanadia groups in the selected model clusters.

Umbrella binding geometries of the vanadia are represented in the calculations by model clusters where the vanadyl group $\mathrm{V}=\mathrm{O}$ of the $\mathrm{VSi}_{7} \mathrm{O}_{13} \mathrm{H}_{7}$ cluster, see Fig. 1a, is replaced by a vanadium binding with a distorted $\mathrm{O}_{2}$ and two $\mathrm{O}$ species which interact with hydroxylated $\mathrm{Si}-\mathrm{OH}$ sites at the support-oxide interface. This results in a model cluster $\mathrm{VSi}_{7} \mathrm{O}_{15} \mathrm{H}_{9}$ shown in Fig. $1 \mathrm{~g}$ In a second model the vanadyl group $\mathrm{V}=\mathrm{O}$ is connected with two $\mathrm{OH}$ groups interacting with hydroxylated $\mathrm{Si}-\mathrm{OH}$ sites at the interface resulting in a model cluster $\mathrm{VSi}_{7} \mathrm{O}_{15} \mathrm{H}_{11}$ shown in Fig. $1 \mathrm{~h}$ These clusters represent the energetically most stable peroxo $(\mathrm{SiO})-\mathrm{V}=\mathrm{O}\left(\mathrm{O}_{2}\right)$ and hydroxylated $(\mathrm{SiO})-\mathrm{V}=\mathrm{O}(\mathrm{OH})_{2}$ umbrella clusters obtained by extended DFT geometry optimizations [15]. For comparison and calibration purposes the present cluster studies include calculations on a model cluster $\mathrm{Si}_{8} \mathrm{O}_{25} \mathrm{H}_{18}$, see Fig. 2, representing a local section of $\alpha$-quartz in its bulk geometry. This bulk cluster proposed earlier in theoretical studies [17, 18] is saturated by hydrogen to simulate $\mathrm{Si}-\mathrm{O}$ binding at its periphery. Bond lengths and angles in this cluster correspond to experimental values determined by X-ray diffraction [19]. 


\subsection{NEXAFS spectrum calculations}

Electronic ground and core excited states of the above clusters are calculated within the density-functional theory (DFT) scheme together with generalized gradient corrected exchange and correlation functionals (revised Perdew-Burke-Ernzerhof (RPBE) approach [20, 21]). The Kohn-Sham orbitals are represented by linear combinations of atomic orbitals (LCAO) using extended basis sets of contracted Gaussians. For the evaluation of X-ray absorption spectra vanadium, silicon and hydrogen are represented by all-electron double-zeta-valence-pluspolarization (DZVP) basis sets while for oxygen different basis sets are used. At the core excited oxygen center we choose IGLO-III type ([7s6p2d]) basis sets [22] in order to adequately describe inner shell relaxation effects while the other oxygen centers in the cluster are accounted for by effective core potentials (ECPs) for the $1 \mathrm{~s}$ shell and [3s3p1d] valence basis sets to avoid 1s core orbital mixing $[23,24]$. For all calculations the DFT cluster code StoBe [25] is employed.

The evaluation of theoretical O 1s X-ray absorption spectra for the surface clusters is based on core to unoccupied orbital excitations which result from dipole transitions. Hence, angle-resolved spectral intensities I(E, e $)$ are determined by corresponding dipole transition matrix elements, vectors $\underline{\mathrm{m}}=\left(\mathrm{m}_{\mathrm{x}}, \mathrm{m}_{\mathrm{y}}, \mathrm{m}_{\mathrm{z}}\right)$, together with angle-dependent factors describing the polarization vector $\underline{\mathrm{e}}=\left(\mathrm{e}_{\mathrm{x}}, \mathrm{e}_{\mathrm{y}}, \mathrm{e}_{\mathrm{z}}\right)$ of the incoming radiation, i.e. by

$\mathrm{I}(\mathrm{E}, \underline{\mathrm{e}})=\alpha \cdot \mathrm{E} \cdot(\underline{\mathrm{m}} \underline{\mathrm{e}})^{2}, \underline{\mathrm{m}}=\left\langle\varphi_{f}|\mathrm{q} \cdot \underline{\underline{r}}| \varphi_{\text {core }}\right\rangle$

Here $\mathrm{E}$ denotes the transition energy, $\alpha$ is a global scaling factor, and the transition dipole vectors $\underline{m}$ involve the initial core orbital $\varphi_{\text {core }}$ and final excited state orbitals $\varphi_{f}$. For the present purpose the complex dependence of the spectral intensities on the photon polarization direction can be ignored due to the disordered arrangement of the vanadia particles to be considered. Therefore, the angle averaged intensity given by

$\mathrm{I}(\mathrm{E})=\int \mathrm{I}(\mathrm{E}, \underline{\mathrm{e}}) \mathrm{d} \Omega=2 \pi / 3 \cdot \alpha \cdot \mathrm{E} \cdot\left(\mathrm{m}_{\mathrm{x}}{ }^{2}+\mathrm{m}_{\mathrm{y}}{ }^{2}+\mathrm{m}_{\mathrm{z}}{ }^{2}\right)$

and summed over all possible final state orbitals $\varphi_{f}$ will be used in the analysis. The calculation of core excited final states and corresponding matrix elements $\underline{m}$ is performed within Slater's transition potential approach [26, 27] in combination with a double basis set technique [28, 29]. This approach implies the use of a half occupied $\mathrm{O} 1 \mathrm{~s}$ core orbital at the ionization site, thereby accounting for partial electronic relaxation due to the presence of the excited electron. It has been proven earlier that, within this approach, final state relaxation effects are taken care of up to second order in the energy achieving a balance between the two relaxation mechanisms, core and valence type [26, 30]. The computed orbital energies and corresponding dipole transition matrix elements in (2) are convoluted using Gaussian broadening of varying width to simulate instru- mental, vibrational, and life-time broadening. A full-widthat-half-maximum (fwhm) value of $1 \mathrm{eV}$ is applied below the ionization threshold while the broadening is increased linearly to $6 \mathrm{eV}$ within $20 \mathrm{eV}$ above threshold and kept fixed at this value for higher energies. In Slater's transition potential approach the electronic core hole relaxation of the excited final state is not fully accounted for. This incomplete relaxation can be corrected in an approximate way by shifting all excitation energies by the difference of the ionization potential evaluated with the transition potential method and the corresponding value from $\Delta$ Kohn-Sham $(\triangle \mathrm{SCF})$ calculations which results in a global downward shift of about $2 \mathrm{eV}$. Further, relativistic corrections are included by applying an additional upward shift of the computed spectra by $0.33 \mathrm{eV}$ [31].

The present computational approach has been used successfully to yield highly accurate results for X-ray absorption of light atoms in gas phase molecules [30, 32, 33]. It has also been used to study properties of hydrogenbonded systems [30, 34, 35], of adsorbates on metal surfaces $[36,37]$, and of differently coordinated oxygen sites near vanadium and molybdenum oxide surfaces [38-40]. Further details concerning the methods can be found in the corresponding references.

\section{Experimental -Details}

\subsection{Synthesis of the silica-supported vanadia}

For detailed preparation and characterization procedures of the silica SBA-15 supported vanadia catalyst we refer the reader elsewhere [41-44]. In short, the preparation of this model material was performed via controlled grafting/anion-exchange, which consists of functionalization of SBA-15 by 3-aminopropyltrimethoxysilane (APTMS), subsequent anion-exchange of decavanadate into the pores of the silica matrix and thermolysis of the precursor material. This approach allows to precisely control the amount of vanadium introduced into the material over a broad range of vanadia loadings (0-22 wt. \% V) [43]. A SBA-15 reference sample was prepared with the same procedure as described above. However, potassium oxalate monohydrate (Fluka, $>99.5 \%$ ) was introduced in the material instead of decavanadate in the ion-exchange step.

Due to its well-defined preparation the present vanadia catalyst seems adequately suited as a realistic model to gain new insights into the nature of the active sites as well as relation between structural properties and activity in partial oxidation reactions. In fact, contrary to many other structurally simple but rather inert model systems used in literature, the SBA-15 supported vanadia was shown to yield excellent catalytic activity in the propane to acrylic acid as well as in methanol to formaldehyde oxidation reactions $[44,45]$. 


\subsection{NEXAFS measurements}

In situ NEXAFS measurements have been performed at the synchrotron radiation facility BESSY (Berliner Elektronenspeicherringgesellschaft für Synchrotronstrahlung $\mathrm{m}$. b. H.) using monochromatic radiation of the ISISS (Innovative Station for In Situ Spectroscopy) beamline as a tuneable X-ray source. High pressure soft X-ray absorption spectra were measured in the presence of oxygen at elevated temperature using the high pressure station designed and constructed at the Fritz-Haber Institute, Berlin. Details of the setup are described elsewhere [46]. In brief, pellets of VOx/SBA-15 samples are mounted inside a reaction cell onto a sapphire sample holder approximately $2 \mathrm{~mm}$ in front of the $1^{\text {st }}$ aperture of a differentially pumped electrostatic lens system. The home-built electron lens serves as the input system for a modified commercial hemispherical electron analyser (PHOIBOS 150, Specs-GmbH). Oxygen is introduced to the cell via calibrated mass flow controllers, heating is provided by a NIR laser at the rear of the sample, and the temperature is monitored by a thermocouple attached directly to the sample surface. The $\mathrm{O}_{2}$ pressure in the XAS chamber was 0.5 mbar and the heating rate was $5 \mathrm{~K} / \mathrm{min}$ up to the final temperature of $400^{\circ} \mathrm{C}$. V $2 \mathrm{p}$ (Ledge) and $\mathrm{O} 1 \mathrm{~s}$ (K-edge) excitation spectra have been obtained in the Auger electron yield mode by using the electron spectrometer as a detector to minimize contributions from the gas phase to the spectra. O-K edge spectra of the sample surface have been corrected for the remaining effects of $\mathrm{O}_{2}$ gas phase absorption. Further details of the metrology and data treatment will be presented elsewhere [47].

\section{Results and Discussion}

Before examining the silica-supported vanadia particles we validate our methods for pure silicon dioxide by considering $\alpha$-quartz bulk whose structure is well known [19] and where experimental NEXAFS spectra are available in the literature [48]. Fig. 2 compares the calculated oxygen $1 \mathrm{~s}$ core excitation spectrum for a $\mathrm{Si}_{8} \mathrm{O}_{25} \mathrm{H}_{18}$ model cluster proposed earlier in theoretical studies [17, 18] with corresponding experimental $\mathrm{O} \mathrm{K}$-edge NEXAFS data for the monocrystalline $\alpha$-quartz obtained in ref. [48]. Obviously, the agreement in the energy range between 532 and $538 \mathrm{eV}$ is very good considering the fact that an absolute energy scale without adjustment between theory and experiment is used. The experimental spectrum shows additional intensity at energies well above ionization threshold (indicated by a vertical dashed line in Fig. 2) which is not accounted for by theory. This disagreement can be explained by the fact that the theoretical spectrum refers to core excitations at a single oxygen center inside the model cluster while in the measured crystalline $\alpha$-quartz there is some structural disorder leading to oxygen centers with slightly different local environments. This affects corresponding core excitations and can result in additional broa- dening of the NEXAFS profile. The theoretical spectrum in Fig. 2 presents a small peak near $534.5 \mathrm{eV}$ that is not reproduced by experiment. An analysis of the final state orbitals of corresponding core excitations reveals dominant contributions from $\mathrm{OH}$ at the cluster periphery. Therefore, this feature is identified as a cluster artifact due to the hydrogen saturation of peripheral Si-O bonds in the model cluster $[17,18]$. It is expected to disappear with increasing cluster size while the remainder of the spectrum will remain unaffected.

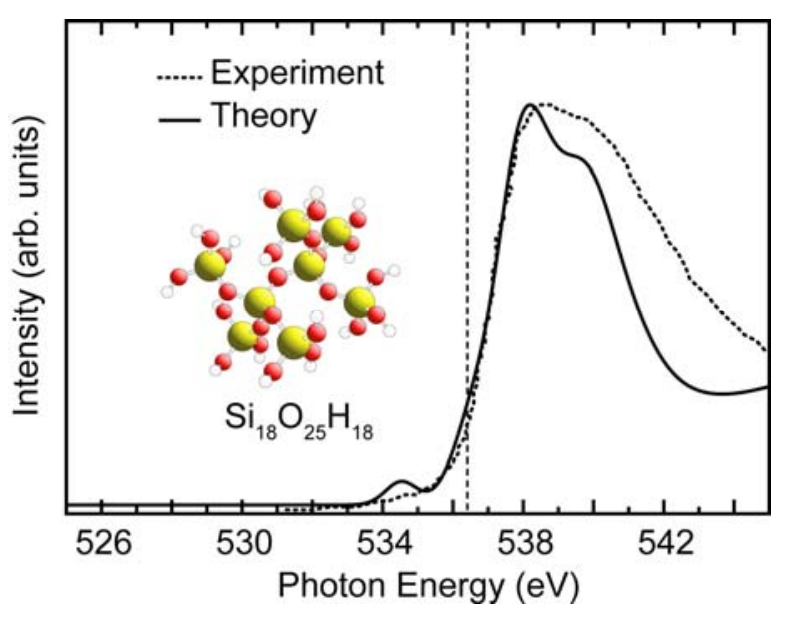

Fig. 2: Comparison of the theoretical oxygen 1s core excitation spectrum (solid line) evaluated for a $\mathrm{Si}_{8} \mathrm{O}_{25} \mathrm{H}_{18}$ cluster (shown in the inset) with an experimental $\mathrm{O}$ K-edge NEXAFS spectrum for $\alpha$-quartz [48] (dotted line), see text. The vertical dashed line indicates the ionization threshold of the theoretical spectrum.

As a first model system of the silica-supported vanadia species we consider the $\mathrm{V}_{2} \mathrm{Si}_{6} \mathrm{O}_{14} \mathrm{H}_{6}$ cluster, see Fig. $1 \mathrm{~b}$, which simulates particles containing dimeric vanadia units and offering four different oxygen species indicated in Fig. 3 , singly coordinated $\mathrm{O}(1)$ of the vanadyl groups $\mathrm{V}=\mathrm{O}(1)$ as well as doubly coordinated $\mathrm{O}(2)$ in bridging $\mathrm{V}-\mathrm{O}(2)-\mathrm{V}$, $\mathrm{V}-\mathrm{O}(2)-\mathrm{Si}$, and $\mathrm{Si}-\mathrm{O}(2)-\mathrm{Si}$ groups. Fig. 3 shows theoretical $\mathrm{O} 1 \mathrm{~s}$ excitation spectra from the different oxygen species revealing considerable variations which allow discriminating between the species. The spectral contributions due to core excitations at vanadyl oxygen $\mathrm{O}(1)$ and oxygen $\mathrm{O}(2)$ bridging two vanadium atoms are focused energetically in the region below $534 \mathrm{eV}$ and carry only little intensity at higher energies. The $\mathrm{O} 1 \mathrm{~s}$ excitation spectrum of the vanadyl oxygen is characterized by a large peak centered at $530.7 \mathrm{eV}$ with a much smaller low energy shoulder while the spectrum due to $\mathrm{V}-\mathrm{O}(2)-\mathrm{V}$ bridging oxygen presents a more complex broad peak structure between 530 and 533 $\mathrm{eV}$. The excitation spectrum related to oxygen bridging between vanadium and silicon, denoted by $\mathrm{V}-\mathrm{O}(2)-\mathrm{Si}$ in Fig. 3, which can be attributed to the vanadia - silica interface, is described by a smaller two-peak structure of $2 \mathrm{eV}$ separation centered near $531 \mathrm{eV}$ and a much larger twopeak structure (of $3 \mathrm{eV}$ separation) above $535 \mathrm{eV}$. Finally, oxygen bridging between silicon, denoted by $\mathrm{Si}-\mathrm{O}(2)-\mathrm{Si}$ in 


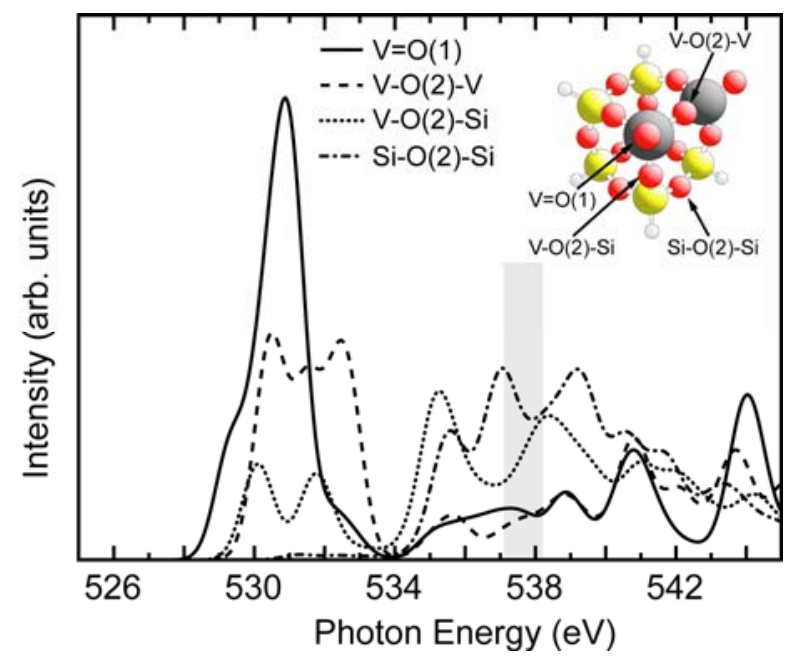

Fig. 3: Theoretical $\mathrm{O} 1 \mathrm{~s}$ excitation spectra calculated for four different oxygen species, $\mathrm{V}=\mathrm{O}(1), \mathrm{V}-\mathrm{O}(2)-\mathrm{V}, \mathrm{V}-\mathrm{O}(2)-\mathrm{Si}$, and $\mathrm{Si}-$ $\mathrm{O}(2)-\mathrm{Si}$, of the dimer cluster $\mathrm{V}_{2} \mathrm{Si}_{6} \mathrm{O}_{14} \mathrm{H}_{6}$, see Fig. 1b. The light gray vertical block indicates the energy range of the computed ionization potentials of the different sites.

Fig. 3, and connected with the silica support contributes a core excitation spectrum represented by a broad multi-peak structure above $535 \mathrm{eV}$ near the excitation threshold.

Altogether, the $\mathrm{O} 1 \mathrm{~s}$ core excitation contributions to the $\mathrm{O}$ K-edge NEXAFS spectrum of the $\mathrm{V}_{2} \mathrm{Si}_{6} \mathrm{O}_{14} \mathrm{H}_{6}$ model cluster allow a clear distinction between differently coordinated and differently binding oxygen species which allows a clear spectroscopic discrimination. First, oxygen binding with vanadium, both vanadyl and bridging type, contributes intensity in the energy region below $534 \mathrm{eV}$ while energies above $534 \mathrm{eV}$ are characterized mainly by contributions from binding with silicon, analogous to the findings for pure silica, see Fig. 2. Oxygen connecting between vanadium and silicon (and representing the vanadia-silica interface) contributes both above and below $534 \mathrm{eV}$ with the high-energy contribution being more prominent. Second, the spectra of the different V-O contributions below $534 \mathrm{eV}$ differ substantially in their energy dependence such that they should be easily discernable in a well resolved experimental NEXAFS spectrum. In particular, the theoretical data indicate that spectral intensity near $533 \mathrm{eV}$ could be attributed to bridging $\mathrm{V}-\mathrm{O}(2)-\mathrm{V}$ species characterizing polymeric vanadia groups and may, thus, be used to identify polymeric vanadia by $\mathrm{O}$ K-edge NEXAFS experiments.

The electronic coupling of vanadia and silica at the interface of the $\mathrm{V}_{2} \mathrm{Si}_{6} \mathrm{O}_{14} \mathrm{H}_{6}$ model cluster after oxygen core excitation can be studied in some detail by examining typical final state orbitals of $1 \mathrm{~s}$ core excitations of oxygen bridging between vanadium and silicon (denoted by $\mathrm{V}$ $\mathrm{O}(2)-\mathrm{Si}$ in Fig. 3). Fig. 4 combines the corresponding excitation spectrum taken from Fig. 3 with iso-surface plots of representative final state orbitals for excitation energies referring to peaks 1 - 3. Obviously, the two peaks 1,2 in the lower energy region can be assigned to core excitations where the final state orbitals are described by anti-bonding mixtures of $\mathrm{V} 3 \mathrm{~d}$ with $\mathrm{O} 2 \mathrm{p}$ contributions without notice

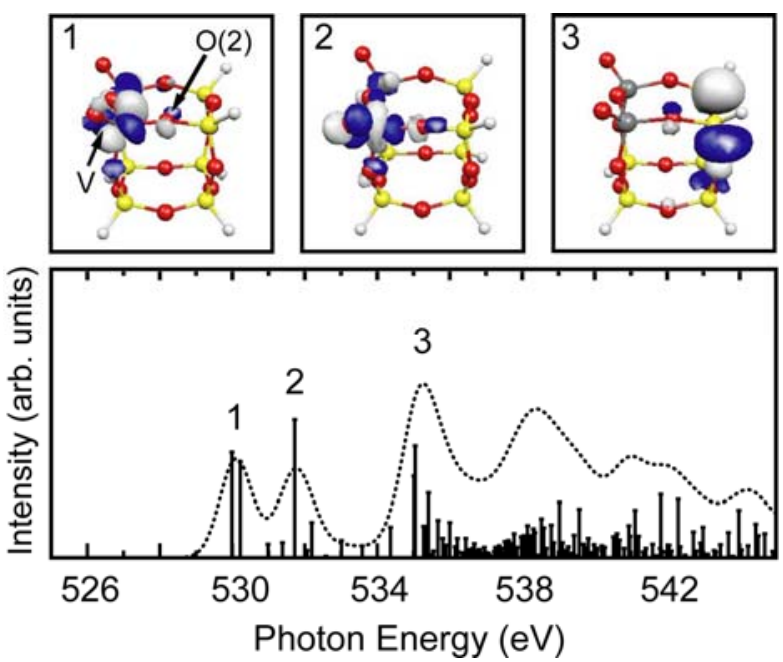

Fig. 4: Theoretical O 1s NEXAFS spectrum of oxygen bridging between vanadium and silicon, $\mathrm{V}-\mathrm{O}(2)-\mathrm{Si}$, for the dimer cluster $\mathrm{V}_{2} \mathrm{Si}_{6} \mathrm{O}_{14} \mathrm{H}_{6}$ as taken from Fig. 3 together with iso-surface plots of representative final state orbitals for excitation energies of peaks 1 - 3. The full lines in the spectrum indicate the calculated excitation energies with their heights showing relative excitation probabilities.

ble participation of the Si partner. On the other hand, peak 3 is characterized by final state orbitals which are antibonding mixtures of $\mathrm{Si} 3 \mathrm{p}$ with $\mathrm{O} 2 \mathrm{p}$ with no $\mathrm{V}$ contributions. The orbitals of the peak near $538 \mathrm{eV}$ close to ionization threshold are found to be rather diffuse with some emphasis in the Si-O bond regions. Thus, the calculations suggest a clear energetic separation between the core excitations involving vanadium and silicon.

The conclusions reached so far from the calculations on the dimer cluster $\mathrm{V}_{2} \mathrm{Si}_{6} \mathrm{O}_{14} \mathrm{H}_{6}$ are of general validity and apply also to other model clusters. As an example, Fig. 5 compares computed $\mathrm{O}$ 1s core excitation spectra for the four pyramidal clusters taken from ref. [7], see Fig. 1a-d. The spectra (A) of Fig. 5 for singly coordinated $\mathrm{O}(1)$ of the vanadyl groups $\mathrm{V}=\mathrm{O}(1)$ show minor variations only near the top of the main peak at $531 \mathrm{eV}$ and for energies beyond $542 \mathrm{eV}$ well above ionization threshold. The spectra (B) of Fig. 5 for doubly coordinated $\mathrm{O}(2)$ of the $\mathrm{V}-\mathrm{O}(2)-\mathrm{Si}$ bridges, characteristic for the vanadia - silica interface, differ only in some detail for energies higher than $536 \mathrm{eV}$, again near or above ionization. Finally, the spectra (C) of Fig. 5 for doubly coordinated $\mathrm{O}(2)$ of the $\mathrm{Si}-\mathrm{O}(2)-\mathrm{Si}$ bridges, which contribute intensity only at higher energies and characterize the silica substrate, depend also only weakly on cluster geometry described by slight discrepancies in bond lengths and angles. Altogether, the overall shapes of the spectra for all three oxygen sites agree quite closely for the different clusters referring to both monomeric and dimeric $\mathrm{VO}_{\mathrm{x}}$ species.

Dimeric vanadia units are modeled in this work by three model clusters, see Figs. 1b-d, where the geometry of the $\mathrm{V}-\mathrm{O}(2)-\mathrm{V}$ bridges differs mainly by the $\mathrm{V}-\mathrm{O}(2)-\mathrm{V}$ bond angle $\theta$, see Table 1 . This affects details of corresponding $\mathrm{O}$ 1s core excitation spectra as shown in Fig. 6. The energy 
(A) $\mathrm{V}=\mathrm{O}(1)$

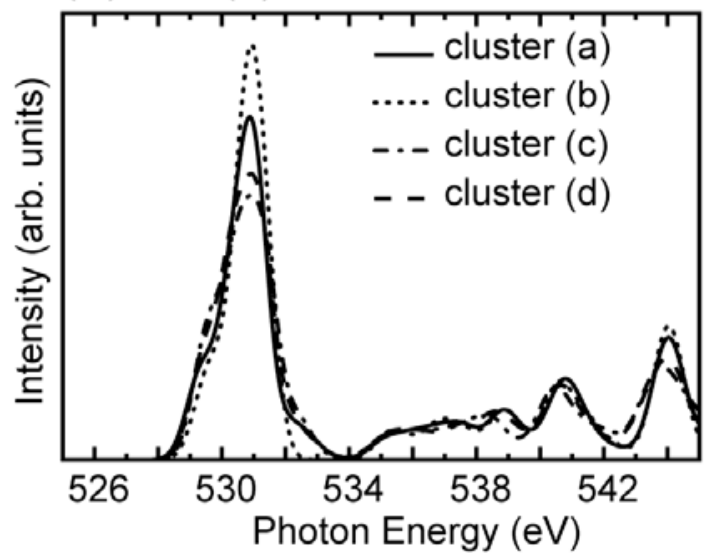

(C) $\mathrm{Si}-\mathrm{O}(2)-\mathrm{Si}$

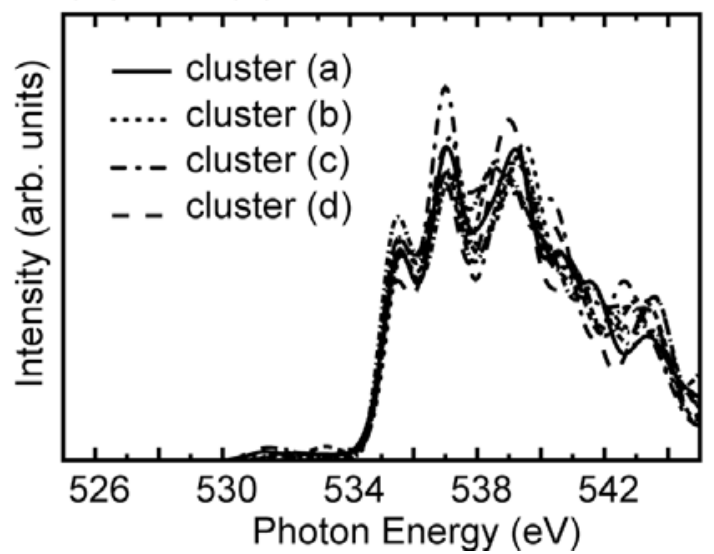

(B) $\mathrm{V}-\mathrm{O}(2)-\mathrm{Si}$

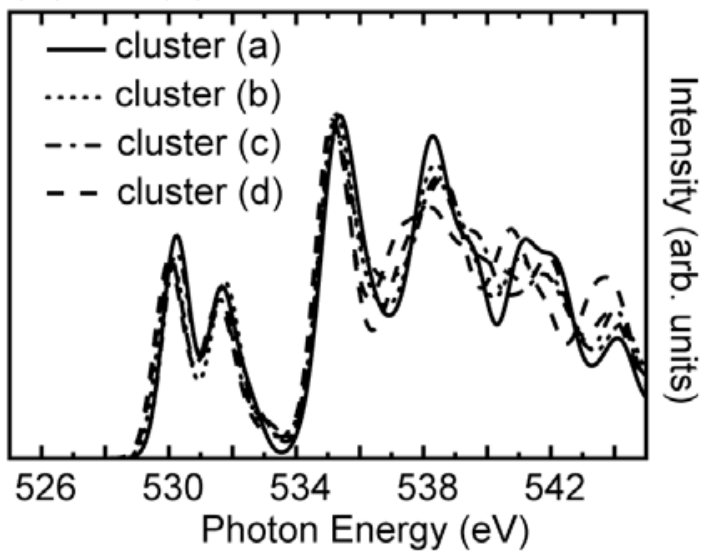

Fig. 5: Theoretical O 1s NEXAFS spectra of non-equivalent oxygen sites, (A) V=O(1), (B) V-O(2)-Si, and (C) Si-O(2)-Si present in the model clusters (a) to (d), see Fig. 1. Spectra of the different sites inside the same cluster are represented by the same line type.

range between 530 and $533 \mathrm{eV}$ of the excitation spectra is described by a three-peak structure, denoted $1-3$ in Fig. 6 , where the lowest peak 1 remains essentially unchanged while peaks 2 and 3 depend more strongly on the bond angle $\theta$. This behavior can be understood partly by the local symmetry of the corresponding final state orbitals included in Fig. 6. For the following, we introduce a local Cartesian coordinate system, sketched in Fig. 6, with the $\mathrm{O}(2)$ center in its origin, the $\mathrm{x}$ axis pointing between the two $\mathrm{V}$ centers of the $\mathrm{V}-\mathrm{O}(2)-\mathrm{V}$ bridge, and the $\mathrm{z}$ axis lying in the plane through $\mathrm{V}, \mathrm{O}(2), \mathrm{V}$. The $\mathrm{y}$ axis is perpendicular to $\mathrm{x}$ such that changed $\mathrm{V}-\mathrm{O}(2)-\mathrm{V}$ bond angles $\theta$ correspond to rotations about the $y$ axis. In this coordinate system final state orbitals characterizing peak 1 are described by anti-bonding mixtures of $\mathrm{O} 2 \mathrm{p}_{\mathrm{y}}$ with $\mathrm{V} 3 \mathrm{~d}_{\mathrm{xy}}$ functions, see Fig. 6 . As a consequence, their shape, and hence transition probabilities defining the corresponding peak intensity, depend only little on the $\mathrm{V}-\mathrm{O}(2)-\mathrm{V}$ bond angle $\theta$. The final state orbitals determining peak 2 are described by anti-bonding mixtures of $\mathrm{O} 2 \mathrm{sp}_{\mathrm{z}}$ (variety $2 \mathrm{a}$ of Fig. 6) or O $2 \mathrm{p}_{\mathrm{x}}$ (variety $2 \mathrm{~b}$ ) with $\mathrm{V}$ $3 \mathrm{~d}_{\mathrm{x} 2-\mathrm{y} 2}$ functions where the latter contribute about the same intensity to peak 2 for different angles $\theta$. In contrast, the influence of variety $2 \mathrm{a}$ to the $\theta$ dependence of peak 2 is more pronounced. According to the Walsh rules [49] for $\mathrm{AB}_{2}$ molecules corresponding orbitals with $\mathrm{sp}_{\mathrm{z}}$ type contributions at center $A$ will reduce their $p$ character when the BAB angle $\theta$ approaches $180^{\circ}$ (yielding a linear ABA molecule). This effect is seen in the $\mathrm{V}-\mathrm{O}(2)-\mathrm{V}$ groups of the clusters where the $\mathrm{O} 2 \mathrm{p}$ contributions to the final states orbitals become smaller for larger angles $\theta$. Thus, the intensity for $\mathrm{O}(2)$ 1s core excitations, determined by dipole selection rules involving $\mathrm{O} 2 \mathrm{p}$, is diminished which reduces peak 2 for increasing angles $\theta$ as evidenced in Fig. 6. Further, final state orbitals determining peak 3 are described by anti-bonding mixtures of $\mathrm{O} 2 \mathrm{p}_{\mathrm{x}}$ (variety $3 \mathrm{a}$ of Fig. 6) or $\mathrm{O}$ $2 p_{z}$ (variety $3 b$ ) with $\mathrm{V} 3 \mathrm{~d}_{\mathrm{z} 2}$ functions where both orbital types contribute $\theta$ dependent intensity in a complex way such that overall peak 3 increases in intensity as $\theta$ increases. Altogether, the dependence of the V-O(2)-V peak structure on the bond angles $\theta$ is quite obvious and may be used to obtain additional geometric information on the bridging oxygen species from highly resolved experimental O Kedge NEXAFS spectra without recurring to polarization dependent measurements. 


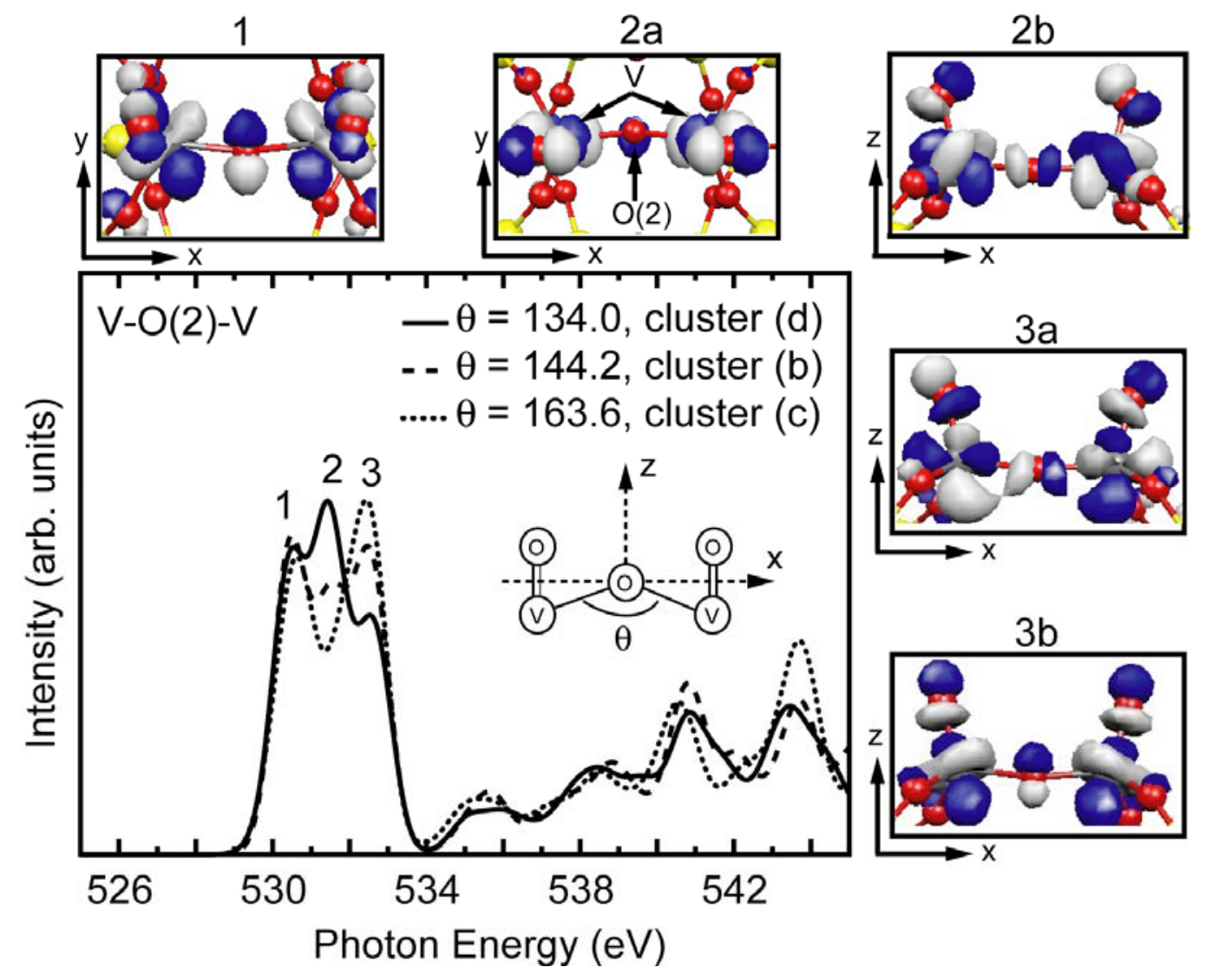

Fig. 6: Theoretical O 1s NEXAFS spectra of the bridging V-O(2)-V species for model clusters (b), (c), (d), see Fig. 1, together with iso-surface plots of representative final state orbitals for excitation energies of peaks 1 - 3.The inset lists V-O-V bond angles $\theta$ (in degrees) in the different clusters. The coordinate systems of the views are indicated accordingly.

The present theoretical results are used to interpret the NEXAFS spectra obtained for silica SBA-15 supported vanadia model catalysts. The top curve (a) of Fig. 7 shows a measured NEXAFS spectrum of the vanadium-free SBA15 support revealing only one asymmetric peak near 538 $\mathrm{eV}$. Based on the theoretical NEXAFS spectra for a model cluster representing bulk $\alpha$-quartz, discussed above, as well as considering experimental NEXAFS spectra for $\alpha$-quartz [48] the asymmetric peak can be understood as due to oxygen $1 \mathrm{~s}$ core excitations of Si-O-Si bridges in the SBA-15 support. Curve (b) of Fig. 7 shows a measured NEXAFS spectrum of SBA-15 supporting surface vanadia species with a weight loading of $10.8 \% \mathrm{~V}\left(4.7 \mathrm{~V} / \mathrm{nm}^{2}\right)$. (It must be noted that corresponding spectra obtained for lower loading, $2.7 \mathrm{wt} \% \mathrm{~V}\left(0.7 \mathrm{~V} / \mathrm{nm}^{2}\right)$ [47], do not yield any significant differences.) The difference spectrum, denoted (c) in Fig. 7, can be taken as representative for the surface vanadia species itself and is available for an analysis based on the present spectrum calculations. This spectrum (c) shows a multi-peak structure with peaks between $516 \mathrm{eV}$ and 528 $\mathrm{eV}$ assigned to vanadium $\mathrm{L}$ edge excitations, i. e. $\mathrm{V} 2 \mathrm{p} \rightarrow \mathrm{V}$ $3 \mathrm{~d}$, in analogy to results from experimental and theoretical studies on other vanadium oxides $[38,50]$. These excitations cannot be accounted for by the present theoretical approach as a consequence of missing spin-orbit coupling required for a proper description of the (relativistic) $\mathrm{V} 2 \mathrm{p}_{1 / 2}$ and $2 \mathrm{p}_{3 / 2}$ orbitals. In contrast, the broad asymmetric peak between $528 \mathrm{eV}$ and $534 \mathrm{eV}$ is, based on the present theoretical analysis, clearly due to oxygen 1 s core excitations in the vanadia species.

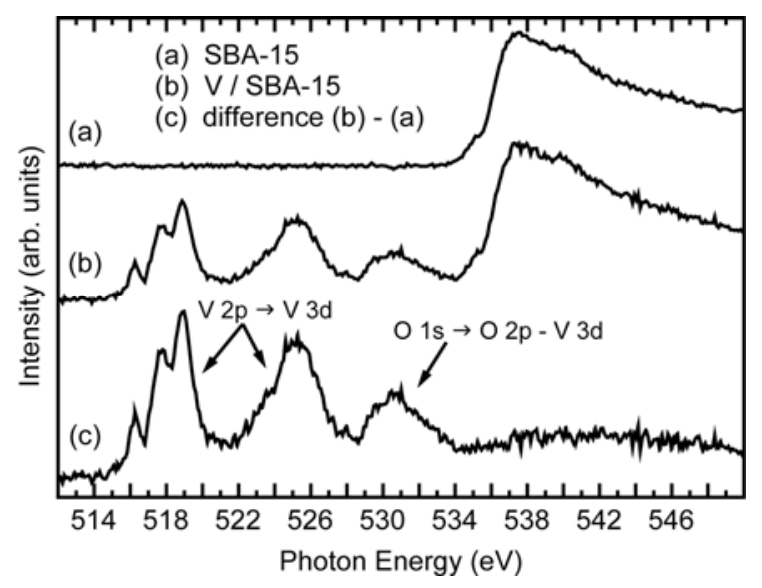

Fig. 7: Experimental NEXAFS spectra of (a) clean SBA-15 support, (b) SBA-15 with vanadia particles (V / SBA-15, 10.8\% V weight loading). The difference spectrum (b) - (a) characterizes the vanadia contributions with different core excitation regions labeled accordingly. 

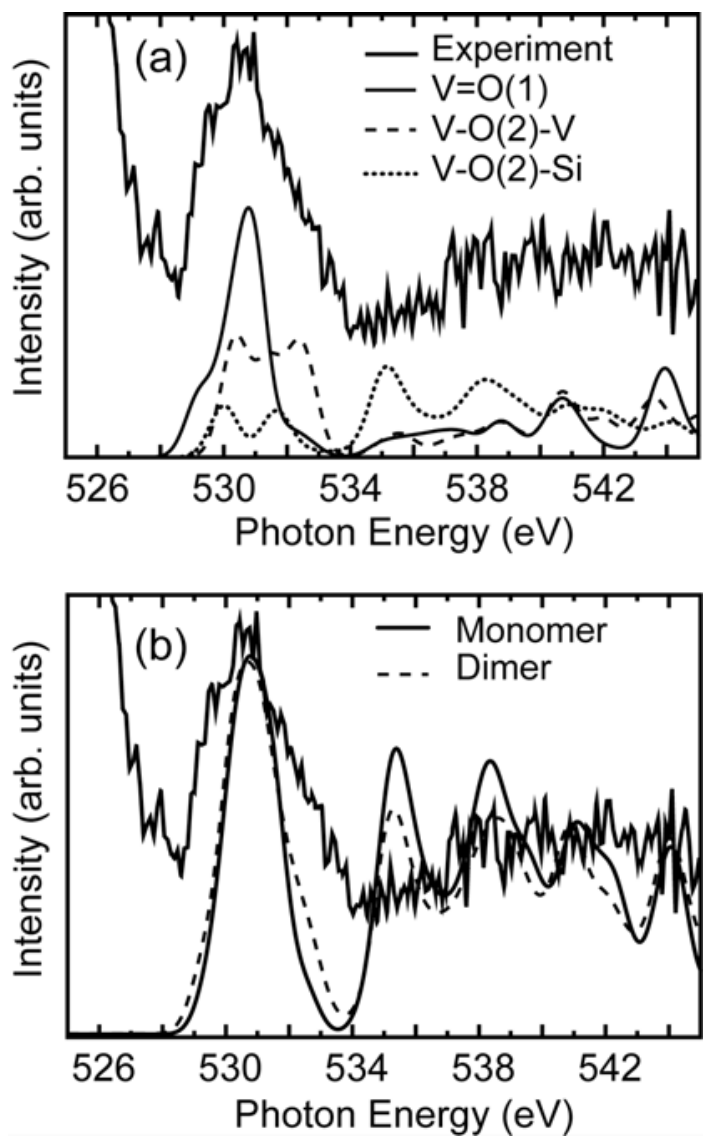

Fig. 8: (a) Comparison of the experimental difference spectrum (c) of Fig. 7 with theoretical $1 \mathrm{~s}$ core excitation spectra of the different oxygen species inside the model dimer cluster $\mathrm{V}_{2} \mathrm{Si}_{6} \mathrm{O}_{14} \mathrm{H}_{6}$, see Fig. $1 \mathrm{~b}$. The spectral contributions refer to vanadyl oxygen $\mathrm{V}=\mathrm{O}(1)$ and oxygen in $\mathrm{V}-\mathrm{O}(2)-\mathrm{V}$ and $\mathrm{V}-\mathrm{O}(2)-\mathrm{Si}$ bridges, respectively, see Fig. 3. (b) Comparison of the experimental difference spectrum (c) with stoichiometry-weighted superpositions of oxygen core excitation spectra computed for the dimer cluster $\mathrm{V}_{2} \mathrm{Si}_{6} \mathrm{O}_{14} \mathrm{H}_{6}$ and for the monomer cluster $\mathrm{VSi}_{7} \mathrm{O}_{13} \mathrm{H}_{7}$, see text. All curves have been normalized to yield the same peak maximum at $530.5 \mathrm{eV}$.

Fig. 8a compares the experimental difference spectrum (c) of Fig. 7 for the energy range between $526 \mathrm{eV}$ and $542 \mathrm{eV}$ with theoretical oxygen $1 \mathrm{~s}$ core excitation spectra of Fig. 3 referring to the dimer cluster $\mathrm{V}_{2} \mathrm{Si}_{6} \mathrm{O}_{14} \mathrm{H}_{6}$, see Fig. 1b. Obviously, the contributions from differently coordinated oxygen species exhibit characteristic differences, see Fig. 3, and they cover the energy range ( $528 \mathrm{eV}$ to $534 \mathrm{eV})$ where the broad asymmetric peak is observed in the experimental NEXAFS spectrum. In particular, the low-energy shoulder below $530 \mathrm{eV}$ in the experimental spectrum as well as the peak center at $530.7 \mathrm{eV}$ can be assigned to excitations from vanadyl oxygen $\mathrm{O}(1)$ while the intensity in the high-energy tail near $533 \mathrm{eV}$ may be explained to a major extent by excitations from oxygen in $\mathrm{V}-\mathrm{O}(2)-\mathrm{V}$ bridges. Further, intensity in the energy range between $534 \mathrm{eV}$ and $540 \mathrm{eV}$ of the experimental spectrum can be interpreted to be mainly due to excitations from oxygen in $\mathrm{V}-\mathrm{O}(2)-\mathrm{Si}$ bridges characterizing the $\mathrm{VO}_{\mathrm{x}}$-support interface. However, a direct quantitative comparison of the experimental O Kedge NEXAFS spectrum with the theoretical partial $\mathrm{O} 1 \mathrm{~s}$ spectra of the dimer model cluster $\mathrm{V}_{2} \mathrm{Si}_{6} \mathrm{O}_{14} \mathrm{H}_{6}$ by itself is questionable for different reasons. First, the comparison must be based on stoichiometry-weighted superpositions of the partial spectra where for $\mathrm{V}_{2} \mathrm{Si}_{6} \mathrm{O}_{14} \mathrm{H}_{6}$ the total spectral intensity is given by

$\boldsymbol{I}_{\mathrm{tot}}=2 \boldsymbol{I}[\mathrm{V}=\mathrm{O}(1)]+\boldsymbol{I}[\mathrm{V}-\mathrm{O}(2)-\mathrm{V}]+4 \boldsymbol{I}[\mathrm{V}-\mathrm{O}(2)-\mathrm{Si}]$

This reduces the relative importance of the contribution due to $1 \mathrm{~s}$ excitations at the bridging $\mathrm{O}(2)$ species, dominating the partial spectra near $533 \mathrm{eV}$ in Fig. 8a, in favor of those at $\mathrm{O}(1)$, which is evident from Fig. $8 \mathrm{~b}$ (dashed curve) and makes the comparison less satisfactory. Second, the measurements refer to supported vanadia species of an unknown distribution between mono- and different polymeric species without a clear preference. So other vanadia species have to be considered in the comparison. Fig. $8 \mathrm{~b}$ includes, apart from the experimental O K-edge spectrum and the theoretical dimer spectrum, the stoichiometryweighted superposition of oxygen core excitation spectra computed for the monomer cluster $\mathrm{VSi}_{7} \mathrm{O}_{13} \mathrm{H}_{7}$ according to

$\boldsymbol{I}_{\text {tot }}=\boldsymbol{I}[\mathrm{V}=\mathrm{O}(1)]+3 \boldsymbol{I}[\mathrm{V}-\mathrm{O}(2)-\mathrm{Si}]$

where all curves have been normalized to yield the same peak maximum at $530.7 \mathrm{eV}$. Obviously, both theoretical spectra give a width of the main peak which is too small (applying the standard broadening of $1.0 \mathrm{eV}$ ) compared with experiment. The additional intensity at the highenergy side of the dimer peak due to core excitations from oxygen in $\mathrm{V}-\mathrm{O}(2)-\mathrm{V}$ bridges makes only a small contribution to the broadening. This contribution is expected to increase if vanadia species with longer $\mathrm{VO}_{\mathrm{x}}$ polymer chains are considered where stoichiometry factors determining the relative contributions but also electronic effects have to be taken into account. This has been confirmed in calculations on $\mathrm{V}_{\mathrm{x}} \mathrm{O}_{\mathrm{y}}$ trimer and tetramer models, see Figs. 1e, f, where detailed analyses [51] show that electronic hybridization of adjacent $\mathrm{V}-\mathrm{O}(2)-\mathrm{V}$ bridges in the polymers increases the spectral intensity on the high-energy side of the main peak near $531 \mathrm{eV}$ supporting the asymmetric shape of the experimental peak. The effect can bee seen in Fig. 9 which compares the total theoretical $\mathrm{O}$ 1s excitation spectra for the vanadia parts in the different model clusters, $\mathrm{VO}_{\mathrm{x}}$ monomer to tetramer (see Figs. 1a, b, e, f), with the experimental O K-edge NEXAFS spectrum. (All theoretical spectra have been normalized according to the total number of oxygen centers in the clusters.)

A full theoretical account of the asymmetric tail of the experimental main peak may require including also contributions from clusters with other local $\mathrm{VO}_{\mathrm{x}}$ geometry. Recently, so-called "umbrella" geometries of the $\mathrm{VO}_{\mathrm{x}}$ unit have been suggested [9-11] on the basis of vibrational, UVvis, and EXAFS analyses where vanadia binds with only one V-O-Si bond bridge at the support interface rather than with three in the pyramidal geometry. Here we model the umbrella geometry by clusters $\mathrm{VSi}_{7} \mathrm{O}_{15} \mathrm{H}_{9}$ (including a peroxo group, $\mathrm{V}=\mathrm{O}_{2}$, see Fig. $1 \mathrm{~g}$ ) and $\mathrm{VSi}_{7} \mathrm{O}_{15} \mathrm{H}_{11}$ (including 


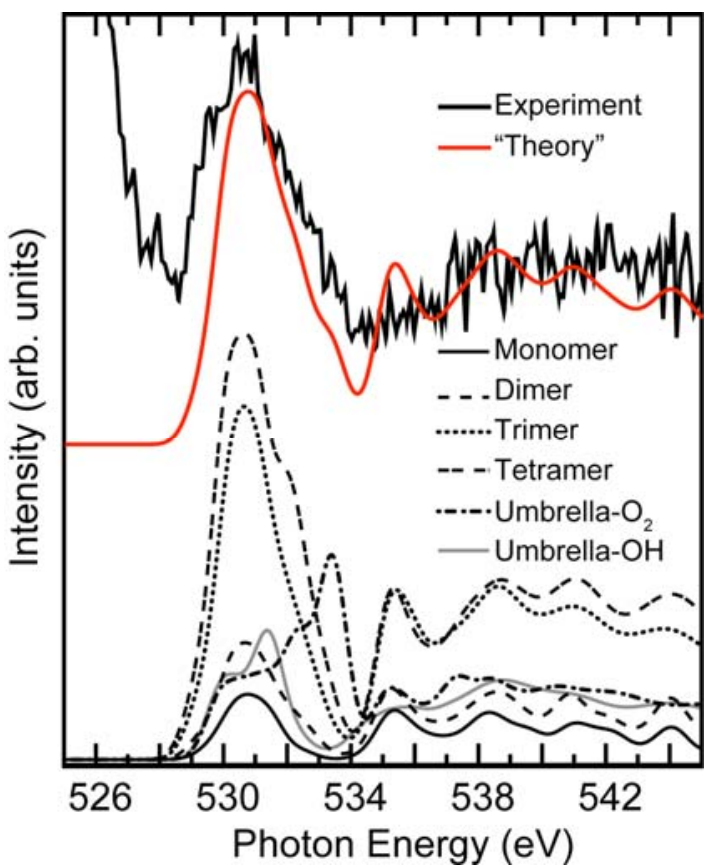

Fig. 9: Comparison of the experimental difference spectrum (c) of Fig. 7 with theoretical $\mathrm{O}$ 1s core excitation spectra of the different model clusters, (a) monomer, (b) dimer, (e) trimer, (f) tetramer, (g) umbrella- $\mathrm{O}_{2}$, (h) umbrella-OH shown in Fig. 1. All theoretical spectra have been normalized according to the total number of oxygen centers in the clusters. The curve labeled "Theory" refers to a superposition of all six cluster spectra with equal weight, see text.

two hydroxyl groups, V-OH, see Fig. 1h) as discussed earlier. Fig. 9 includes total theoretical 1s excitation spectra of the two model clusters. The spectrum obtained for the $\mathrm{VSi}_{7} \mathrm{O}_{15} \mathrm{H}_{9}$ cluster, denoted "Umbrella- $\mathrm{O}_{2}$ " and given by a dash-dotted line in Fig. 9, exhibits a dominant multi-peak structure between $530 \mathrm{eV}$ and $533.5 \mathrm{eV}$ where the largest peak near $533.5 \mathrm{eV}$ is assigned to oxygen of the peroxo group $\mathrm{V}=\mathrm{O}_{2}$ and lies clearly above the main peaks of the mono- to tetramer clusters, see Fig. 9. While there are indications from experiment [52] that vanadium peroxo compounds may be thermally unstable under equilibrium conditions they could well exist under constant oxygen pressure at $400^{\circ} \mathrm{C}$ and contribute additional intensity to the high energy tail of the experimental peak.

The $\mathrm{VSi}_{7} \mathrm{O}_{15} \mathrm{H}_{11}$ cluster simulating the hydroxyl variant $(\mathrm{SiO})-\mathrm{V}=\mathrm{O}(\mathrm{OH})_{2}$ of the umbrella structure, see Fig. $1 \mathrm{~h}$, offers oxygen belonging to the vanadyl group, $\mathrm{V}=\mathrm{O}(1)$ as well as oxygen in hydroxylated groups, V-OH. The resulting total theoretical $\mathrm{O} 1 \mathrm{~s}$ excitation spectrum is included in Fig. 9 as a gray line denoted "Umbrella-OH". It is characterized by a two-peak structure between $529 \mathrm{eV}$ and $531.5 \mathrm{eV}$ resulting from excitations at oxygen in $\mathrm{V}=\mathrm{O}(1)$ and also $\mathrm{V}-\mathrm{OH}$ groups. Further, there is a broad band extending beyond $536 \mathrm{eV}$ described by final state orbitals localized at the $\mathrm{OH}$ group. Altogether, spectral contributions originating from the model cluster of $\mathrm{V}-\mathrm{OH}$ umbrella structure do not yield new aspects for the $\mathrm{O}$ 1s excitation spectrum of the vanadia particles.

The theoretical multi-peak structures of Fig. 9 in the energy range between $534 \mathrm{eV}$ and $542 \mathrm{eV}$ are found, for all model clusters, to be due to core excitation at oxygen in interface $\mathrm{V}-\mathrm{O}(2)-\mathrm{Si}$ bridges. However, the overall peak heights in this energy range compared with those of the main peaks near $531 \mathrm{eV}$ differ significantly between the different clusters. Since the relative amount of interface bridges is the largest in the vanadia monomer cluster the corresponding multi-peak structure between $534 \mathrm{eV}$ and $542 \mathrm{eV}$ is the most prominent compared with the main peak and its relative importance gets smaller for the larger polymer clusters, see Fig. 9. In fact, assuming vanadia monomer particles to exist exclusively or dominate at the SBA15 surface the spectral contributions from interface $\mathrm{V}-\mathrm{O}(2)$ Si bridges should be large enough to be observable in the experimental O K-edge NEXAFS spectrum. This is illustrated in Fig. 8b where the theoretical monomer spectrum shows a peak structure between $534 \mathrm{eV}$ and $542 \mathrm{eV}$ which lies clearly outside the noise of the experimental spectrum. This may suggest that in the experiment the relative amount of monomeric $\mathrm{VO}_{\mathrm{x}}$ species present at the SBA-15 surface is small compared with that of other species.

One final aspect concerning the interpretation of the strongly asymmetric main peak near $531 \mathrm{eV}$ in the experimental O K-edge NEXAFS spectrum of the vanadia/SBA15 system, see Fig. 9, refers to the influence of thermal effects. Since the measurements have been carried out at elevated temperatures of $400^{\circ} \mathrm{C}$ thermal vibrations of the vanadia particles have to be considered and lead to a smearing of the corresponding NEXAFS peaks depending on the vibrational amplitudes of the atoms inside the particles. A rough estimate of this thermal smearing has been obtained in model studies on the dimer cluster $\mathrm{V}_{2} \mathrm{Si}_{6} \mathrm{O}_{14} \mathrm{H}_{6}$, see Fig. $1 \mathrm{~b}$, where theoretical oxygen $1 \mathrm{~s}$ core excitation spectra of the vanadyl group $\mathrm{V}=\mathrm{O}(1)$ were calculated for different $\mathrm{V}$ $\mathrm{O}$ distances. (The spectrum for the V-O equilibrium distance is shown in Fig. 3, full line.) Distance variations $\Delta \mathrm{d}$ of up to $\pm 0.1 \AA$ with respect to the equilibrium value are found to shift the spectra rigidly where the shift scales linearly with $\Delta \mathrm{d}$ at an increment of $10 \mathrm{eV} / \AA$. On the other hand, differences in the cluster total energy corresponding to $400^{\circ} \mathrm{C}$ result in a $\Delta \mathrm{d}$ value of $\pm 0.05 \AA$ and hence to a spectral shift value of about $\pm 0.5 \mathrm{eV}$. Therefore, thermal effects are not considered to be important for the interpretation of the asymmetric main peak near $531 \mathrm{eV}$ in the experimental O K-edge NEXAFS spectrum .

\section{Conclusions}

In this work we present theoretical oxygen 1s core excitation spectra of silica-supported vanadia nanoparticles using DFT cluster techniques and appropriate model clusters simulating both mono- and different polymeric species in pyramidal and umbrella geometry. The excitation spectra of differently coordinated oxygen species, vanadyl $\mathrm{V}=\mathrm{O}(1)$, 
bridging $\mathrm{V}-\mathrm{O}(2)-\mathrm{V}$ and $\mathrm{V}-\mathrm{O}(2)-\mathrm{Si}$, as well as $\mathrm{V}-\mathrm{O}_{2}$ and $\mathrm{V}-$ $\mathrm{OH}$, are found to differ considerably as to their shapes and energy distributions. Thus, they can be used to distinguish between the species in a well resolved experimental spectrum. The theoretical spectra are then compared with in situ NEXAFS measurements on silica SBA-15 supported vanadia model catalysts in the presence of oxygen at $400{ }^{\circ} \mathrm{C}$ allowing the identification of corresponding structural properties.

Based on the theoretical analysis, spectral contributions from oxygen in the vanadia species are found to be well separated energetically from those of $\mathrm{Si}-\mathrm{O}(2)-\mathrm{Si}$ bridges in the silica support such that the two species can be discriminated unambiguously in the measured NEXAFS spectra. This is a clear advantage over vibrational analyses of infrared or Raman spectra [7] where vibrational $\mathrm{V}=\mathrm{O}$ and $\mathrm{Si}-\mathrm{O}$ bands overlap and make a distinction between monomeric, polymeric $\mathrm{V}_{\mathrm{x}} \mathrm{O}_{\mathrm{y}}$ species and the $\mathrm{SiO}_{2}$ support difficult. Spectral intensity from oxygen core excitations at singly coordinated $\mathrm{V}=\mathrm{O}$ focus in a small energy region about $530.7 \mathrm{eV}$ which agrees very nicely with the location of the central peak in the experimental O K-edge NEXAFS spectrum shown in Fig. 9. (Note that the energy scales applied in theory and in experiment have not been calibrated against each other.) However, the vanadyl contributions are found to be quite similar for the monomer and polymer model clusters which do not allow a clear distinction between the different vanadia species on the basis of the vanadyl contributions alone.

Spectral contributions from oxygen core excitations at $\mathrm{V}-\mathrm{O}(2)-\mathrm{V}$ bridges, characteristic of vanadia polymer species, are shifted to higher energies and extend over a wider range compared with excitations at vanadyl oxygen, a common feature of all polymer clusters considered in the calculations. This contributes to the asymmetric shape of the main peak in the experimental O K-edge NEXAFS spectrum of Fig. 9. However, the extra intensity at the highenergy side of the theoretical polymer peaks due to core excitations from oxygen in $\mathrm{V}-\mathrm{O}(2)-\mathrm{V}$ bridges cannot fully explain the asymmetric shape. Additional intensity at the high-energy side of the main peak may be due to oxygen $1 \mathrm{~s}$ core excitations of vanadia species in umbrella geometries [8-11] claimed to coexist with pyramidal species. This is confirmed by spectrum calculations for appropriate model clusters reflecting a peroxo structure $\mathrm{V}=\mathrm{O}_{2}$ as well as hydroxilated species [15] yielding sizeable intensity in the energy region of the high-energy tail of the experimental main peak shown in Fig. 9. In fact, a superposition of the oxygen core excitation spectra of all six model clusters considered in this work (with equal weight) results in a spectrum labeled "Theory" in Fig. 9 which gives an almost quantitative account of the experimental spectrum. While this agreement is quite suggestive it cannot be called sound. (Hence the "quotes" in the label.) First, the set of the present model clusters cannot be called exhaustive in regard of possible representatives of the vanadia particles under real experimental conditions. Second, a superposition of the spectra with equal weights is doubtful. However, the fact that a successful interpretation of the experimental $\mathrm{O}$ K-edge NEXAFS spectrum requires the coexistence of different vanadia species can be safely deduced from the present work.

Spectral contributions from oxygen core excitations at $\mathrm{V}-\mathrm{O}(2)-\mathrm{Si}$ bridges characterizing the vanadia - silica interface dominate for excitation energies larger than 534 $\mathrm{eV}$, i. e above the main peak in the experimental O K-edge NEXAFS spectrum of Fig. 9. However, the overall peak heights in this energy range compared with those of the main peaks near $531 \mathrm{eV}$ differ significantly between the different clusters. In particular, assuming vanadia monomer particles to dominate at the SBA-15 surface the spectral contributions from interface $\mathrm{V}-\mathrm{O}(2)-\mathrm{Si}$ bridges should be large enough to be observed in the experimental O K-edge NEXAFS spectrum but cannot be found. This suggests strongly that the experimental spectrum is not consistent with mainly monomeric vanadia species residing at the SBA-15 substrate. These findings are supported by recent EXAFS measurements on the same samples [53] where short $\mathrm{V}-\mathrm{V}$ distances $(<3.5 \AA)$, compatible with $\mathrm{V}-\mathrm{O}(2)-\mathrm{V}$ bridges of di- or polymeric vanadia species, have been detected.

Altogether, the present theoretical results together with O K-edge NEXAFS measurements suggest that different vanadia species will coexist at the SBA-15 support where, as a result of the complexity of these materials, a quantitative estimate of the relative composition is not possible so far. However, the existence of only or mainly one type of vanadia particle, in particular monomeric species, at the SBA-15 support can be clearly ruled out. Theoretical and experimental studies of other vanadia reference compounds, such as vanadates whose structures and degree of polymerization is well known, may help to get deeper inside into the structure of supported vanadia catalyst. Studies along these lines are currently under way.

\section{Acknowledgement}

This work was partly supported by the Deutsche Forschungsgemeinschaft (DFG) through its Sonderforschungsbereich 546, "Transition metal oxide aggregates". One of the authors (M. C.) acknowledges financial support from the Alexander-von-Humboldt foundation. C. H. thanks the DFG for providing an Emmy-Noether fellowship. The BESSY staff is acknowledged for continuously supporting the synchrotron based high pressure electron spectroscopy experiments of the Fritz-Haber Institute. 


\section{References}

[1] G. C. Bond and S. F. Tahir, Appl. Catal. 71 (1991) 1.

[2] G. Deo, I. E. Wachs, and J. Haber, Crit. Rev. in Surf. Chem. 4 (1994) 141

[3] B. M. Weckhuysen and D. E. Keller, Catal. Today 78 (2003) 25.

[4] A. Dinse, B. Frank, C. Hess, D. Habel, R. Schomäcker, Appl. Catal. A (2008) accepted

[5] I. E. Wachs, Catal. Today 27 (1996) 437.

[6] A. Khodakov, B. Olthof, A. T. Bell, and E. Iglesia, J. Catal. 181 (1999) 205.

[7] N. Magg, B. Immaraporn, J. B. Giorgi, T. Schroeder, M. Bäumer, J. Döbler, Z. L. Wu, E. Kondratenko, M. Cherian, M. Baerns, P. C. Stair, J. Sauer, and H. J. Freund, J. Catal. 226 (2004) 88.

[8] D. E. Keller, T. Visser, F. Soulimani, D. C. Koningsberger, and B. M. Weckhuysen, Vib. Spectr. 43 (2007) 140.

[9] O. L. J. Gijzeman, J. N. J. van Lingen, J. H. van Lenthe, S. J. Tinnemans, D. E. Keller, and B. M. Weckhuysen, Chem. Phys. Lett. 397 (2004) 277.

[10] J. N. J. van Lingen, O. L. J. Gijzeman, B. M. Weckhuysen, and J. H. van Lenthe, J. Catal. 239 (2006) 34.

[11] J. N. J. van Lingen, O. L. J. Gijzeman, R. W. A. Havenith, and J. H. van Lenthe, J. Phys. Chem. C 111 (2007) 7071.

[12] T.V. Venkov, C. Hess, F.C. Jentoft, Langmuir 23 (2007) 1768.

[13] J. Stöhr, "NEXAFS spectroscopy", Springer, Berlin; New York, 1992.

[14] . Y. Ying, C. P. Mehnert, and M. S. Wong, Angew. Chem., Int. Ed. 38 (1999) 56.

[15] J. Döbler and J. Sauer, in preparation.

[16] C. Baerlocher, W. M. Meier, and D. H. Olsen, "Atlas of Zeolite Framework Types", Elsevier, Amsterdam, 2001.

[17] G. Pacchioni, A. M. Ferrari, and G. Ierano, Faraday Disc. 106 (1997) 155.

[18] R. M. Van Ginhoven, H. Jonsson, K. A. Peterson, M. Dupuis, and L. R. Corrales, J. Chem. Phys. 118 (2003) 6582.

[19] L. Levien, C. T. Prewitt, and D. J. Wiedner, Am. Mineralogist 65 (1980) 920 .

[20] B. Hammer, L. B. Hansen, and J. K. Norskov, Phys. Rev. B 59 (1999) 7413-7421.

[21] J. P. Perdew, K. Burke, and M. Ernzerhof, Phys. Rev. Lett. 77 (1996) 3865

[22] W. Kutzelnigg, U. Fleischer, and M. Schindler, "NMR Basic Principles and Progress" Springer, Berlin; New York, 1990.

[23] M. Nyberg, Ph.D. Thesis, Stockholm University, 2000.

[24] L. G. M. Pettersson, U. Wahlgren, and O. Gropen, J. Chem. Phys. 86 (1987) 2176.

[25] K. Hermann, L. G. M. Pettersson, M. E. Casida, C. Daul, A. Goursot, A. Koester, E. Proynov, A. St-Amant, D. R. Salahub, V. Caravetta, H. Duarte, C. Friedrich, N. Godbout, J. Guan, C. Jamorski, M. Leboeuf, M. Leetmaa, M. Nyberg, L. Pedocchi, F. Sim, L. Triguero and A. Vela, StoBe software, http://www.fhiberlin.mpg.de/ hermann/StoBe/, 2005.

[26] J. C. Slater and K. H. Johnson, Phys. Rev. B 5 (1972) 844.

[27] J. C. Slater, Adv. Quant. Chem. 6 (1972) 1.

[28] L. Triguero, L. G. M. Pettersson, and H. Ågren, J. Phys. Chem. A 102 (1998) 10599.
[29] L. Triguero, L. G. M. Pettersson, and H. Ågren, Phys. Rev. B 58 (1998) 8097.

[30] . Cavalleri, M. Odelius, D. Nordlund, Å. Nilsson, and L. G. M. Pettersson, Phys. Chem. Chem. Phys. 7 (2005) 2854.

[31] O. Takahashi and L. G. M. Pettersson, J. Chem. Phys. 121 (2004) 10339.

[32] C. Kolczewski, R. Püttner, M. Martins, A. S. Schlachter, G. Snell, M. Sant'Anna, K. Hermann, and G. Kaindl, J. Chem. Phys. 124 (2006) 034302.

[33] C. Kolczewski, R. Püttner, O. Plashkevych, H. Ågren, V. Staemmler, M. Martins, G. Snell, A. S. Schlachter, M. Sant'Anna, G. Kaindl, and L. G. M. Pettersson, J. Chem. Phys. 115 (2001) 6426.

[34] M. Cavalleri, L. Å. Naslund, D. C. Edwards, P. Wernet, H. Ogasawara, S. Myneni, L. Öjamäe, M. Odelius, A. Nilsson, and L. G. M. Pettersson, J. Chem. Phys. 124 (2006) 194508

[35] P. Wernet, D. Nordlund, U. Bergmann, M. Cavalleri, M. Odelius, H. Ogasawara, L. Å. Näslund, T. K. Hirsch, L. Ojamae, P. Glatzel, L. G. M. Pettersson, and A. Nilsson, Science 304 (2004) 995.

[36] H. Öström, H. Ogasawara, L. A. Näslund, L. G. M. Pettersson, and A. Nilsson, Phys. Rev. Lett. 96 (2006) 146104.

[37] T. Schiros, S. Haq, H. Ogasawara, O. Takahashi, H. Öström, K. Andersson, L. G. M. Pettersson, A. Hodgson, and A. Nilsson, Chem. Phys. Lett. 429 (2006) 415.

[38] C. Kolczewski and K. Hermann, Surf. Sci. 552 (2004) 98.

[39] C. Kolczewski and K. Hermann, J. Chem. Phys. 118 (2003) 7599.

[40] M. Cavalleri, K. Hermann, S. Guimond, Y. Romanyshyn, H. Kuhlenbeck, and H. J. Freund, Catal. Today 124 (2007) 21.

[41] C. Hess, G. Tzolova-Müller, and R. Herbert, J. Phys. Chem. C 111 (2007) 9471.

[42] C. Hess, J. D. Hoefelmeyer, and T. D. Tilley, J. Phys. Chem. B 108 (2004) 9703.

[43] C. Hess, U. Wild, and R. Schlögl, Microp. Mesop. Mater. 95 (2006) 339

[44] C. Hess, I. J. Drake, J. D. Hoefelmeyer, T. D. Tilley, and A. Bell, Catal. Lett. 105 (2005) 1.

[45] C. Hess, M. H. Looi, S. B. Abd Hamid, and R. Schlögl, Chem. Comm. 4 (2006) 451.

[46] H. Bluhm, M. Hävecker, A. Knop-Gericke, M. Kiskinova, R. Schlögl, M. Salmeron, MRS bulletin 2007, 7, 602.

[47] C. Hess, M. Hävecker and R. Schlögl, in preparation

[48] F. Bart, F. Jollet, J. P. Duraud, and L. Douillard, Phys. Stat. Solidi B 176 (1993) 163.

[49] A. D. Walsh, J. Chem. Soc. (1953) 2288.

[50] C. Kolczewski and K. Hermann, Theor. Chem. Acc. 114 (2005) 60.

[51] M. Cavalleri, J. Döbler, and K. Hermann, to be published.

[52] D. Joniakova and P. Schwendt, Thermochim. Acta 92 (1985) 701.

[53] A. Walter, R. Herbert, C, Hess, and T. Ressler, in preparation. 